\title{
0
}

OLHARES

REVISTA DO DEPARTAMENTO DE EDUCAÇÄO - UNIFESP

\section{SIGNIFICAÇÕES DE JOVENS GAYS RICOS E POBRES SOBRE A}

MASCULINIDADE NA ESCOLA

\author{
SIGNIFICACIONES DE JÓVENES GAYS RICOS Y POBRES ACERCA DE LA \\ MASCULINIDAD EN LA ESCUELA
}

POOR AND RICH YOUNG GAYS MEANINGFULNESS ABOUT

MASCULINITY AT SCHOOL

\author{
Marcos Martins Amaral \\ Pontifícia Universidade Católica de São Paulo \\ amaral.m.marcos@gmail.com \\ Ana Mercês Bahia Bock \\ Pontifícia Universidade Católica de São Paulo \\ abock@pucsp.br
}

\begin{abstract}
Resumo: Este artigo apresenta pesquisa realizada sobre o papel da escola na constituição da masculinidade gay. Para isto estudamos as significações constituídas por estudantes autodeclarados gays, suas experiências e vivências na escola, enfocando a constituição de sua orientação sexual. O estudo considerou também o fato de vivermos em uma sociedade marcada pela desigualdade social, acreditando que este aspecto poderia ser determinante nas experiências e significações. Foram realizadas conversações com dois grupos de adolescentes homens autodeclarados gays, pobres e ricos, do Ensino Médio da cidade de São Paulo. As conversações foram analisadas a partir da perspectiva da Psicologia Sócio-Histórica e do procedimento de constituição de Núcleos de Significação. O movimento dialético de análise nos permitiu afirmar que a escola é uma instituição social importante na constituição da masculinidade dos adolescentes gays e precisa superar, institucionalmente, o seu estranhamento às funções sociais que lhe cabe.
\end{abstract}

Palavras-chave: Jovens gays. Masculinidade Gay. Dimensão Subjetiva.

Resumen Este artículo presenta una investigación realizada sobre el papel de la escuela en la constitución de la masculinidad gay. Para eso, estudiamos las significaciones constituidas por los estudiantes homosexuales autodeclarados, sus experiencias y vivencias en la escuela, con centro en la constitución de su orientación sexual. El estudio también consideró el hecho de que vivimos en una sociedad marcada por la desigualdad social, creyendo que este aspecto podría ser determinante en las vivencias y significaciones. Se realizarón conversaciones con dos grupos de homosexuales autodeclarados, pobres y ricos, de la escuela secundaria en la ciudad de Sao Paulo. Las conversaciones fueron analizadas desde la perspectiva de la Psicología Sociohistórica y del procedimiento de constitución de Núcleos de Significaciones. El movimiento dialéctico de análisis permitió afirmar que la escuela es una institución social importante en la constitución de la masculinidad de los adolescentes homosexuales y necesita superar institucionalmente su alejamiento de las funciones sociales de las que es responsable. 
Palabras-Clave: Jóvenes homosexuales. Masculinidad gay. Dimensión subjetiva.

Abstract This article presents research on the school role in the gay masculinity constitution. With that purpose we studied the meanings constituted by self-declared gay students and their experiences at school, focusing on their sexual orientation constitution. The study also considered the fact that we live in a society marked by social inequality, believing that this aspect could be determinant in experiences and meanings. The conversation instrument was applied with two groups of adolescent men selfdeclared gay, poor, and rich from São Paulo city high schools. The results were analyzed through the Social-Historical Psychology perspective by the Nuclei of Meaning procedure. The dialectical movement of analysis allowed us to affirm that the school is a fundamental social institution in the masculinity constitution of gay adolescents and that institutions need to overcome its strangeness regarding their social functions.

Keywords: Young Gay Men. Gay Masculinity. Subjective Dimension.

\section{Introdução}

A pesquisa relatada neste artigo tem como como tema a escola, e o recorte apresentado é a presença da homossexualidade nessa instituição. Um recorte polêmico, sem consensos profundos, com fortes defesas de diferentes posições: de educadores, de pais e mesmo de educandos.

Pesquisas têm apontado que, na escola, há uma extensa rejeição à homossexualidade, principalmente de pessoas do sexo/gênero masculino, por parte de pais, professores, alunos e gestores das escolas (ABRAMOVAY; CASTRO; SILVA, 2004; BORGES et al, 2011; GOMES e LUCCA, 2011; REIS e CARVALHO, 2014). Também tem sido apontado que, na escola, há uma intensa vigilância à heterossexualidade, tida como inata, natural e, por isso, alvo de cuidado, atenção e investimento. Desta forma, meninos são vigiados e incentivados a corresponder a um determinado tipo de masculinidade. Aquele que foge à norma sofre sanções e violências.

Podemos afirmar que a escola tem um papel singular na constituição da masculinidade por ser ela o primeiro espaço de socialização dos meninos, depois da família. Um espaço em que estes se defrontam com as possibilidades e contradições do ser homem. Albertini (2012) ressalta essa contraditoriedade ao explicar que, nesse espaço, os meninos se defrontam com a homofobia ao mesmo tempo em que aparecem as possibilidades de experimentarem práticas homossexuais.

Em outras palavras, a configuração da masculinidade no homem é multideterminada, dando-se no processo de socialização e a escola tem um papel importante, por ser um espaço de descobertas em que o singular encontra possibilidades de constituição e expressão no coletivo. No entanto, essa instituição social é contraditória: ao mesmo tempo em que disciplina 
para a heterossexualidade, é o espaço em que também há possibilidades de subversão dessa ordem, em que os meninos têm a possibilidade de realizar as primeiras práticas homoeróticas.

Em síntese, a homossexualidade é uma realidade nas escolas, no entanto, esse fenômeno existe de forma conflituosa nessa instituição social (ABRAMOVAY; CASTRO; SILVA, 2004; ABRAMOVAY; CASTRO, 2006; BORGES; MEYER, 2008). Nesse sentido, o nosso interesse foi investigar o papel da escola na constituição da masculinidade gay. Para isto, estudamos as significações constituídas por estudantes autodeclarados gays, suas experiências e vivências na escola, enfocando a constituição de sua orientação sexual. Importante ressaltar que, pelo fato de vivermos em uma sociedade marcada pela desigualdade social, partimos do pressuposto de que esse aspecto poderia ser determinante nas experiências e significações dos jovens. Isto posto, teceremos algumas considerações teórico-metodológicas que fundamentaram a pesquisa.

Homens e mulheres transformam o mundo material e, ao fazerem isso, transformamse a si mesmos. O humano precisa ser compreendido na sua inserção social e histórica. $\mathrm{Na}$ Psicologia, para fazermos jus a essa concepção, em um esforço de superar teorias subjetivistas e objetivistas, tomamos a perspectiva crítica da Psicologia Sócio-Histórica, de base materialista histórica e dialética, como fundamento.

Para enriquecer a análise psicológica, trouxemos contribuições das epistemologias feminista materialista francófona e marxista brasileira, que partem de uma compreensão materialista e antinaturalista das relações sociais de sexo/gênero (MATHIEU, 2005; KERGOAT, 2009; CISNE, 2014; LAPA, 2015; SAFFIOTI, 1987; 2015; FALQUET, 2014). Homens e mulheres são seres sociais que se constituem na realidade, ou seja, em condições concretas e determinadas. As relações de sexo/gênero (homem-homem; homem-mulher; mulher-mulher) são reguladas pelo regime hegemônico na sociedade em que se inserem as relações, o que nos permite afirmar que, em nossa sociedade, este regime é patriarcal e heterossexista.

Entendemos patriarcado como um constructo que dá visibilidade ao poder do homem sobre a mulher dando-lhes direitos sexuais sobre elas. É um tipo hierárquico de relação que invade todos os espaços da sociedade, corporificando-se e representando uma estrutura de poder baseada na ideologia e na violência (PATTEMAN, 1993; SAFFIOTI, 1987; 2015). Já o heterossexismo pode ser definido como um princípio de visão de mundo que promove, exclusiva e exaustivamente, a heterossexualidade, atribuindo a esta o monopólio exclusivo da sexualidade humana, ao mesmo tempo em que promove a exclusão da homossexualidade (WELZER-LANG, 2001; 2004; TIN, 2012). 
Desta forma, o heterossexismo e o patriarcado funcionam como um sistema sexopolítico de dominação, denominado heteropatriarcado, que naturaliza sexo/gênero e institucionaliza desejos sexuais que são captados e reproduzidos por dispositivos institucionais. O domínio do heteropatriarcado se instala no corpo, nas percepções e nos desejos dos homens que estão submetidos às práticas disciplinadoras das instituições. Esse sistema naturaliza a heterossexualidade e a desigualdade entre homens e mulheres (POBLETE HERNÁNDEZ, 2014) e entre homens e outros homens, em que o desejo do grande homem (WELZER-LANG, 2001) predomina, subordinando o desejo da mulher e de outros homens que não respondem à lógica heteropatriarcal.

A constituição do masculino se dá, em grande parte, no encontro do homem com outros homens - na casa-dos-homens -, em lugares monossexuados que estruturam 0 masculino de maneira paradoxal, levando os meninos a apreenderem que, para serem verdadeiros homens, eles devem dissociar-se de tudo que faz referência às mulheres. $\mathrm{Na}$ casa-dos-homens é necessário se distinguir dos "[...] fracos, das femeazinhas, dos 'veados', ou seja, daqueles que podem ser considerados como não-homens" (WELZER-LANG, 2001, p.465, destaque do autor). A casa-dos-homens também existe e se expressa na escola (WELZER-LANG, 2001; 2004).

\section{Objetivo e Metodologia}

Este estudo, realizado na Pontifícia Universidade Católica de São Paulo (PUC-SP), buscou compreender a constituição da masculinidade gay na escola. O nosso interesse pela temática da desigualdade social nos levou a acreditar que a constituição dessa masculinidade, em jovens ricos e pobres, que frequentam escolas marcadas também pela desigualdade, se apresenta de maneira diferente, ou seja, é vivida diferentemente, mobiliza afetos distintos e se põe nas relações sociais de modo diferente. Consideramos, portanto, importante, ao estudarmos as significações, levarmos em consideração a desigualdade social.

Compreendemos que na sociedade brasileira a desigualdade é marca estruturante da realidade, posicionamento do grupo de pesquisa do CNPq, Desigualdade Social: suas diversas expressões, a que esta pesquisa se vincula. Nesse sentido, a constituição da masculinidade gay entre ricos e pobres é afirmada, por nós, como diferente, dada a situação desigual que caracteriza suas vivências sociais na escola ou fora dela.

No campo da Psicologia, partimos da Psicologia Sócio-histórica, com fundamentação no materialismo histórico e dialético enquanto epistemologia e método. O princípio dialético 
da contradição e a compreensão materialista de objeto e sujeito sustentam essa abordagem. Tendo a historicidade como noção básica, nosso esforço é superar a dicotomia subjetividadeobjetividade, compreendendo-as como pares dialéticos. Dialética que tem, na categoria mediação, centro organizador de seus processos, marcando o rompimento com as dicotomias (AGUIAR et al, 2015; AGUIAR E OZELLA, 2013; GONÇALVES, 2015a; GONÇALVES, 2015b; BOCK, 2015).

Objetividade e subjetividade são uma unidade de contrários em transformação. $O$ homem aqui é apreendido em sua condição humana, é individual e social ao mesmo tempo, historicamente determinado. Ou seja, o singular expressa e carrega o todo, assim como o todo expressa e carrega o singular em sua multiplicidade de possiblidades, a partir de uma articulação dialética (BOCK, 1999; BOCK, 2015; GONÇALVES, 2015a; ROSA e KAHHALE, 2009).

A opção por trabalhar com meninos do Ensino Médio fundamentou-se no fato deles estarem mais tempo na escola, portanto, terem uma história de constituição de sua masculinidade nessa instituição que trariam elementos, inclusive históricos, sobre o papel da escola na constituição da masculinidade gay. Além disso, os alunos do Ensino Médio estão em uma faixa etária em que as teorias de desenvolvimento no campo da Psicologia reconhecem como o momento em que a sexualidade e as questões que a compõem e norteiam se tornam muito importantes nas preocupações e práticas desses jovens (ALMEIDA e CUNHA, 2003; MAIA et al., 2012).

A escolha dos participantes da pesquisa não foi ao acaso. Foram escolhidos informantes-chave, isto é, aqueles sujeitos que tiveram, a partir de suas singularidades, maiores possibilidades de contribuir com o objetivo do estudo (DENZIN E LINCOLN, 2006; GONZÁLEZ REY, 2005). Desta forma, os sujeitos foram escolhidos a partir de sua implicação com o tema pesquisado, de possuírem características que permitissem aprofundar a compreensão dos objetivos propostos no estudo, além da aceitação declarada de participar da discussão sobre a temática, o que envolvia suas vidas pessoal e privada, e a autodeclaração de orientação sexual homossexual.

Porém, essa escolha dos informantes-chave foi um processo difícil no percurso da pesquisa, dadas as dificuldades existentes na sociedade que constrangem a autodeclaração gay. Isso nos exigiu procedimentos dos mais diversos. Em um primeiro momento, tentamos articulação com as escolas dos bairros de maior e menor índice de exclusão social. No entanto, fomos impedidos, pelos gestores das instituições contatadas, de realizar uma investigação com os objetivos propostos. Decidimos, então, pelo diálogo com professores, que nos auxiliassem encontrar os jovens, que deveriam se autodeclarar gay aos 
pesquisadores no momento do convite, e estes nos auxiliaram a formar os grupos, indicando colegas também gays. Foi mais difícil formar grupo com adolescentes ricos, pois os responsáveis pelos jovens dessa camada social não consentiam, muitas vezes, sua participação, dado o tema da investigação.

Foram formados dois grupos de educandos do Ensino Médio, moradores da cidade de São Paulo, levando em consideração o índice de exclusão social da região de moradia desses jovens a partir do Atlas da exclusão social no Brasil (POCHMANN; AMORIM, 2003; GUERRA; POCHMANN; SILVA, 2015)i. Um dos grupos foi formado com educandos moradores de bairros com alto Índice de Exclusão (pobres); e o outro com educandos moradores de bairros com baixo Índice de Exclusão (ricos).

A classificação dos jovens em pobres e ricos pode parecer imprecisa, porém, sustentamos a escolha desses termos inspirados na ousadia de Jessé Souza (2003; 2006) em utilizar termos que não ocultem ou escamoteiem a abissal desigualdade social brasileira. Os grupos constituídos para o presente trabalho ocupam, na sociedade brasileira, lugares desigualmente hierarquizados e assimétricos, em uma escala de valorização social. Aqueles chamados ricos, no presente estudo, além de morarem e estudarem em bairros com baixo índice de exclusão social da cidade de São Paulo, têm melhores condições econômicas e estudam em escolas particulares com mensalidades que variam de $\mathrm{R} \$ 3000,00$ (três mil reais) a $\mathrm{R} \$ 4.000,00$ (quatro mil reais). Os pais desses jovens têm nível de formação no Ensino Superior e ocupam postos de trabalho com pouca precarização, quando comparados aos postos de trabalho que ocupam os pais e mães dos jovens que compõe o grupo que chamamos de pobres. Os jovens pobres residem e estudam em bairros com alto índice de exclusão da cidade de São Paulo; as escolas frequentadas por eles são, na maioria das vezes, públicas e os pais não têm formação superior.

Por dialogar, em vários aspectos, com o referencial teórico metodológico da Psicologia Sócio-histórica, nos inspiramos na proposta de conversação de González Rey (2005; 2010) enquanto instrumento para a produção de dados. Nesse processo ativo entre pesquisador e participantes, que se constitui a conversação, foi apresentada uma questão ampla disparadora: gostaria que vocês me contassem um pouco sobre a homossexualidade de vocês e como isso apareceu e é vivido na escola.

O encontro para realização da conversação com os jovens pobres ocorreu em dezembro de 2017, em Paraisópolis, na sede de organização social do território, que trabalha com crianças e adolescentes tendo como foco principal a Educação. Participaram dessa conversação quatro jovens, sendo seus nomes fictícios: Antoni - 18 anos, $3^{\circ}$ ano do Ensino Médio, morador do Sacomã, pai mecânico e mãe faxineira. Leandro - 17 anos, $3^{\circ}$ ano do 
Ensino Médio, morador do Sacomã, pai servente de pedreiro e mãe doméstica. RuPaul - 17 anos, $2^{\circ}$ ano do Ensino Médio, morador de Paraisópolis, mãe empregada doméstica. Christian - 18 anos, $3^{\circ}$ ano do Ensino Médio, morador de Ermelino Matarazzo, mãe auxiliar de limpeza. Todos eles se autodeclararam negros e já haviam realizado atividades remuneradas. No entanto, na ocasião da realização da conversação, se afirmavam desempregados.

O encontro para a realização da conversação com os jovens ricos ocorreu em agosto de 2018, em Perdizes, na PUC-SP. Participam desse encontro apenas dois jovens, pelas razões já expostas, sendo seus nomes também fictícios: Bernardo - 17 anos, $2^{\circ}$ ano do Ensino Médio, pai biólogo ambiental e trabalhador da Defesa Civil e mãe contadora. Enrique - 17 anos, $3^{\circ}$ ano do Ensino Médio, mãe bancária aposentada e pai engenheiro de segurança do trabalho. Ambos se autodeclaram brancos. Nenhum já havia exercido atividade remunerada.

As conversações foram gravadas, taquigrafadas e transcritas com a permissão dos participantes e de seus responsáveis (quando menores de 18 anos) por meio de termo de consentimento livre e esclarecido. A pesquisa foi submetida e aprovada pelo comitê de ética e pesquisa, da PUC-SP, sob o parecer de número 3.041.594.

As falas dos sujeitos foram analisadas a partir do procedimento da constituição de Núcleos de Significação, proposta desenvolvida por Aguiar e Ozella (2013) e Aguiar e colaboradores (2015). O processo de produção dos Núcleos partiu da aparência, do imediato do fenômeno, com o objetivo de superá-lo. Desse modo, apoderando-nos da dinâmica e estrutura do objeto, reproduzindo no plano ideal - do pensamento - sua essência (NETTO, 2009).

Nosso movimento dialético de análise teve início com leituras flutuantes do material, passando pela construção dos pré-indicadores, dos indicadores e, finalmente, dos Núcleos de Significação, em um processo sempre articulado, durante todo o procedimento de análise, em um movimento espiral. Foi, portanto, a análise das abstrações que nos permitiram compreender e explicar as múltiplas determinações que constituem o fenômeno social em questão.

É importante ressaltar, como já explicado na introdução, que o materialismo histórico e dialético e a Psicologia Sócio-Histórica ancoraram e sustentaram todo o processo de análise de nossa investigação. Porém, pode chamar a atenção do leitor que nos resultados, também dialogamos com estudos que partem de perspectivas pós-estruturalistas, como já mencionado também na introdução. Isso se tornou necessário porque são hegemônicos, nessas perspectivas pós-modernas, estudos no campo da sexualidade, tendo, portanto, uma vasta literatura. Consideramos importante dialogar com elas. 
A seguir, apresentamos os Núcleos de Significação construídos a partir da análise das conversações. Importante destacar que as conversações de cada grupo foram analisadas separadamente, de modo a dar visibilidade às singularidades dos grupos e explicitar as diferenças e aproximações produzidas pela desigualdade social.

\section{Núcleos de significação dos educandos pobres}

Núcleo 1 - Heterossexismo e homossexualidade: movimento de constituição da masculinidade gay. Esse núcleo reúne as falas que dizem respeito à constituição da masculinidade dos jovens pobres e suas múltiplas e complexas mediações.

Já no período do Ensino Fundamental, os jovens pobres entram em contato com a promoção exaustiva e exclusiva da heterossexualidade. "No Fundamental que eu tinha aquela noção de que homem tem que ficar com mulher e vice-versa" (Leandro). Nesse período, eles vão percebendo que existe um determinado modo de ser homem que precisam reproduzir para não serem excluídos, isolados ou sofrerem violência física e/ou simbólica por não responderem a um determinado estereótipo. "Preciso incorporar um macho para não ser zoado" (Antoni).

Esses jovens relatam o uso de várias táticas utilizadas para esconderem sua homossexualidade das outras pessoas. "Quando você é gay e não quer assumir, você assume uma postura de dominador" (Ru Paul). Isso acontece de diversas formas, todas elas de acordo com um determinado tipo de masculinidade heterossexual e dominante. Muitas vezes, com a construção de relações afetivas com meninas ou práticas machistas e homofóbicas. Eles falam dos meninos do fundão, que parece ser uma síntese de homens que reproduzem práticas que chamamos de masculinidade heterossexista.

Todos os jovens desse grupo tiveram, por diferentes motivos, dificuldades para assumir sua homossexualidade, o que os levou a criar uma série de estratégias para lidar com a questão, muitas vezes, reproduzindo práticas sexistas ou homofóbicas. Nessa lógica, tudo que foge à norma heterossexista deve ser disfarçado para enganar aos outros. "Eu assistia futebol para comentar no outro dia, mas eu não gostava de futebol. Eu sempre gostei de funk, mas rebolar a bunda não podia. Eu era uma pessoa que não era de verdade, eu fingia" (Antoni). É importante ressaltar que, muitas vezes, a comparação com pessoas do sexo/gênero feminino é feita para humilhar os meninos. Isso explicita que, para serem homens, eles precisavam se afastar do feminino ou do que diz respeito à mulher.

O esconderijo, armário, também tem seus limites, uma vez que a escola se apresenta como um espaço singular de experimentação de práticas homoeróticas e constituição da 
masculinidade gay. É na escola que aparecem os primeiros exemplos de práticas homoafetivas com outros meninos. É nessa instituição social que os jovens participantes dessa pesquisa foram se permitindo e se debruçando sobre sua homossexualidade, ao mesmo tempo em que essa homossexualidade era barrada, produzindo diversos medos e angústias. A homofobia é tão intensa que a homossexualidade produz, inclusive, o desejo de aniquilamento da própria existência, “... eu não me aceitava. Eu me olhava no espelho e falava: 'se eu for gay, eu vou morrer. Não quero e não sou obrigado a ser gay'” (Antoni).

No processo de constituição da homossexualidade, em que desejam viver mais cotidiana e intensamente práticas afetivas gays, os meninos se afastam dos colegas heterossexuais e se aproximam das meninas. Nesse momento, as meninas deixam de ser objeto de esconderijo para serem cúmplices dos garotos gays. Aos poucos, eles assumem publicamente a homossexualidade e as meninas passam a ser suas principais parceiras.

Assumir a homossexualidade foi muito potente para a vida dos jovens pobres na escola. Eles afirmaram terem coragem de fazer explícitos enfrentamentos quando se depararam com a homofobia e, por vezes, serem escutados. Além disso, se tornaram referência para outros colegas. "No meu grupo de amigos héteros, quando fazem uma brincadeira [homofóbica], agora, eles me perguntam se eu acho ofensivo e tal" (Ru Paul).

Assumir publicamente ou não a homossexualidade e se permitir experimentar ou não práticas homoeróticas têm múltiplas determinações que dificultam o processo de constituição da masculinidade gay. No entanto, a passagem do Ensino Fundamental para o Médio pareceu ser um momento importante desse processo para os jovens pobres. Durante o Ensino Médio, viver a homossexualidade na escola pareceu-lhes mais possível e potente. No entanto, mesmo se apropriando e falando sobre a potência de assumir a homossexualidade, a homofobia estava presente no cotidiano, produzindo medo e receio, inclusive em suas mães. "Eu me assumi, minha mãe aceitou, mas tem receio de eu sair na rua e não voltar para casa" (Christian). Eles parecem entender o lugar social de vulnerabilidade a que estão submetidos sendo pobres, negros e gays.

Núcleo 02 - Sexo/gênero na escola: lidando com a homossexualidade a partir de móveis marcadores fixos. Esse núcleo aglutina falas que dizem respeito ao modo como os jovens pobres viveram e perceberam como a escola, enquanto instituição social, lida com a homossexualidade e a heterossexualidade.

Os jovens pobres explicitam que a homofobia, vivida por eles na escola, está diretamente relacionada ao modo como essa instituição social compreende a orientação sexual em suas diferentes esferas (equipe gestora, funcionários, professores, etc.). A escola, para esses jovens, expressa uma compreensão da orientação sexual e sexo/gênero que parte 
de marcadores fixos e rígidos, manifestos em práticas homofóbicas, ao mesmo tempo em que promove, mesmo que na maioria das vezes pela via biologizante, debates sobre o tema e procure dar respostas quando os alunos são vítimas de ataques homofóbicos. Por isso, chamamos o núcleo de móveis marcadores fixos. Para explicitar o movimento dialético da própria instituição escolar, que reproduz práticas homofóbicas e, ao mesmo tempo, as nega quando discute o tema ou acolhe o aluno, sem, no entanto, ter superado os marcadores fixos de sexo/gênero e sexualidade.

Os jovens pobres apontaram, durante a conversação, que as escolas particular e pública lidam com a orientação sexual de modos diferentes. Para eles, parece que a escola da elite cuida e acolhe os gays e a pública exclui e sustenta a homofobia. "Eles [gays ricos] não sofrem tanto como a gente por uma questão de educação. Acho que eles têm melhor acesso a esses assuntos" (Leandro).

Afirmam, categoricamente, que a escola foi uma instituição social importante na descoberta de sua homossexualidade e que também deveria ser importante no que tange ao combate à homofobia, uma vez que, geralmente, o primeiro ataque homofóbico que sofrem é vivido nesse espaço. "Muitas pessoas se descobrem [gays] na escola. E também nosso primeiro ataque homofóbico é na escola" (Leandro).

Os jovens pobres compartilharam, durante a conversação, vários momentos em que sofreram homofobia na escola de diferentes atores da instituição, inclusive por parte de professores. Contraditoriamente, a escola abre possibilidades de discussão sobre sexo/gênero e sexualidade. Muitas vezes, a dificuldade de lidar com a temática leva a escola a reduzir a discussão à Saúde ou mesmo a terceirizar o debate para órgãos do serviço de Saúde, não compreendendo que a sexualidade é um fenômeno social também de sua responsabilidade.

Ser gay ou aparentar ser gay - leia-se, fugir da norma heterossexual, na escola, é sofrer homofobia. Parece que a escola pública opta, na maioria das vezes, por mascarar a homofobia e dar respostas que institucionalizam sua prática. Mudar os meninos de sala ou de turno porque sofreram homofobia, prática adotada em muitas instituições escolares, não é dar uma resposta anti-homofóbica, pelo contrário, é sustentá-la.

A escola promove a heterossexualidade. "No Ensino Fundamental, quando ia ter festa junina, quem vão ser os pares? É você menininho com essa menininha" (Christian). Podemos, portanto, afirmar que a homofobia na escola é institucional e acaba por produzir sofrimento e dificuldade na constituição da masculinidade gay. 


\section{Núcleos de significação dos educandos ricos}

Núcleo 01 - Constituindo a masculinidade: um processo de reflexão para a constituição da masculinidade gay. Esse núcleo sintetiza o modo como o grupo de adolescentes gays ricos significa a masculinidade. Eles trouxeram dois importantes espaços institucionais em que a masculinidade é vivida e pensada, a saber: a família e, principalmente, a escola. Produziram significações acerca do modo hegemônico heterossexista que aparece na escola e na família e sobre o modo como vêm se apropriando de sua homossexualidade.

Para os jovens deste grupo, a família é a primeira instituição que naturaliza a heterossexualidade, produzindo, no imaginário, que há apenas um modo de constituição da orientação sexual. Ou seja, o heterossexismo parece ser um importante aspecto na família, que contribui para a constituição da masculinidade dos meninos. "Nas festas de família, por exemplo, perguntam: 'como está a namoradinha?' para os meninos. Já tem esse pré, assumir que todos são héteros" (Bernardo).

Esses jovens reconhecem que a escola, enquanto instituição social, é importante para a constituição da orientação sexual. "Você convive muito com aquelas pessoas e muitos anos. Quando começa a se descobrir [gay], você está na escola. Você começa a ter atração por pessoas na escola" (Bernardo).

A instituição social escola, tal como a família, ensina e (re)produz regras heterossexistas. O grupo afirma que não existe, entre os colegas da escola, outro tipo de relacionamento diferente do heterossexual. "Tem tanto casal hetero [na escola]. Casal gay não" (Enrique). A heterossexualidade parece ser, na escola, a única possibilidade de expressão da orientação sexual, ou, pelo menos, da orientação sexual normal, sendo os gays considerados anormais.

Os jovens ricos, ao falarem sobre o desenvolvimento sexual de outros homens, não se implicam no processo, como se fosse algo distante deles. Falam de práticas que viram acontecer entre outros meninos da escola, mas como se não tivesse acontecido com eles. Parece que a constituição da masculinidade desses jovens foi solitária e apartada dos outros meninos. Eles parecem não se reconhecer nos meninos da escola, se afastam de suas práticas. O grupo de adolescentes gays não pertence à casa-dos-homens, são afastados e proibidos de viver práticas homoeróticas como vividas por outros homens, o que dificulta esse processo.

Foi com as meninas que os jovens ricos constituíram laços de amizade em que a troca de experiência, do ponto de vista da sexualidade, pôde ocorrer. "Foi ouvindo amigas ou a partir da comunidade LGBT que eu fui ouvindo, pedindo conselhos, perguntando como foi 
a experiência deles. E a partir dessas experiências, ouvindo na escola, que fui me identificando com algumas delas e trilhando o caminho da homossexualidade" (Bernardo).

Podemos inferir que eles sentem desejo e/ou atração sexual por outros meninos, mas elaboram o desejo para, posteriormente, permitir que ele se concretize.

Ao falar de suas práticas afetivo-sexuais, elas se apresentam recentes. "Eu não tenho muita experiência. Na verdade, a única vez que eu beijei foi agora" (Bernardo). Talvez serem gays tenha restringido, ao menos até o momento, as possibilidades de viver com certa liberdade o desenvolvimento de sua sexualidade.

Eles afirmam que se sentem seguros e protegidos em um espaço comum LGBT, ao mesmo tempo em que significam que ocupam um lugar de privilégio social que facilita esse sentimento de proteção. "Parece que se eu for branco tem uma certa proteção. Mas se eu for negro já caem mais em cima de mim do que em cima do branco" (Bernardo).

Sobre a segurança para falar na vida, há divergências entre eles. Sobre a família, ela pode ser acolhedora ou há uma preferência em não abordar o assunto. A família é uma instituição social importante, mas ela tem diversas expressões na realidade que apareceram nas falas dos jovens ricos.

Núcleo 02 - Sexo/gênero e educação sexual na escola: movimento mediado por rigidez de papéis sociais e ampliação de possibilidades, uma tentativa de superação. As falas desse núcleo sintetizam as significações dos jovens ricos sobre como a escola apresenta e vive, no seu cotidiano, sexo/gênero masculino e feminino. Há uma tentativa de superação dos papéis fixos, que se expressa por meio de debates na escola ou em aulas sobre a temática, ao mesmo tempo em que no cotidiano da escola, entre os colegas, há expressão e promoção da heterossexualidade.

Em sua experiência da escolarização, os jovens ricos tiveram, durante o Ensino Fundamental e Médio, espaços institucionais em que sexo/gênero e sexualidade foram debatidos ou fizeram parte do currículo. Enrique conta que, na escola em que estudou durante o Ensino Fundamental, havia uma disciplina específica para falar sobre muitos fenômenos sociais que constituem o humano com bastante espaço para discutir sexualidade e orientação sexual. Esses espaços podem fortalecer os meninos na constituição de sua homossexualidade, bem como ampliar as possibilidades de ser homem, heterossexual, a partir da reflexão.

Os jovens ricos indicam que sua escola e seus diferentes atores são abertos ao diálogo e ao enfrentamento de práticas homofóbicas ou preconceituosas. " $A$ minha coordenadora é bem legal e a maioria dos professores também. Se tiver um problema, tipo homofobia, a gente pode chegar e falar para eles da situação" (Enrique). 
Mas, a escola particular, ao mesmo tempo em que constitui espaços educacionais para falar sobre esses fenômenos, também reproduz papéis rígidos de sexo/gênero. Os jovens ricos contam que, nas aulas de Educação Física, por exemplo, meninos e meninas são separados. "Parece que vários tipos de esportes são designados para vários tipos de pessoas, só que futebol só para meninos" (Bernardo). O futebol, se torna, portanto, uma prática que marca a masculinidade no homem.

Mesmo reconhecendo a rigidez em alguns espaços institucionais, esses jovens afirmaram que sua escola é acolhedora e age institucionalmente quando acontece racismo, homofobia ou machismo. "Porque a escola é aberta e toma decisões abertas a todos, que vão agradar a todos, então, se tem homofobia, se tem machismo, se tem racismo, a escola toma ação, a escola é ativa" (Bernardo).

Ao falar da escola pública, os jovens ricos dizem acreditar que esta não abre possibilidades de diálogo sobre o tema. "A gente ter abertura para discutir sobre isso é um privilégio que a gente tem e eles [pobres] não têm. Não tem espaço onde eles consigam falar e debater sobre isso" (Bernardo). Eles significam ser potente a escola ter espaços institucionais possibilitem o diálogo e o debate sobre diferentes fenômenos sociais que atravessam o humano. Para eles, esses espaços podem reduzir ou impedir preconceitos e sofrimentos na escola.

Para eles, a escola pública é colocada no lugar da impossibilidade. Sua prática é naturalizada, bem como a pobreza. Eles afirmam que os meninos de escolas públicas tendem a não reclamar quando são vítimas de homofobia porque não serão acolhidos. "Por que falar com alguém dentro da escola se eu tenho mais chances de ser atacado do que de ser entendido? Porque aqui a gente tem mais chance de ser entendido do que atacado" (Bernardo).

\section{A título de conclusão}

A escola se mostrou um importante espaço de constituição da masculinidade dos dois grupos de jovens. A maneira como esses jovens significam o modo como suas respectivas instituições escolares apresentam e lidam com a homossexualidade nos permite compreender os diferentes modos de constituição da masculinidade dos gays ricos e pobres. Além disso, temos as informações e significações desses jovens sobre como a escola trabalha com sexo/gênero e educação sexual.

Há intensa vigilância da heterossexualidade na escola, tanto do rico quanto do pobre; essas instituições educacionais se contextualizam vigilantes e colonizadoras, produzindo 
processos de heterossexismo e homofobia que excluem LGBTs (LACERDA, 2018). É nesse contexto que os meninos, ricos e pobres, constituem sua masculinidade. A escola foi, para ambos os grupos, um importante espaço no que tange à constituição da masculinidade gay, com aproximações e diferenças importantes marcadas pela desigualdade social e decorrente experiência desigual de escolarização. Nosso estudo nos permitiu apontar diferenças importantes da escola do rico e da escola do pobre, explicitando as contradições da instituição escolar quando lida com a homossexualidade.

Os meninos pobres vão se forjando homens gays, principalmente, a partir de experiências vividas, também e principalmente, na escola, por meio da apropriação de uma cultura socialmente compreendida como gay: ouvir um determinado tipo de música, por exemplo. Esses meninos possuem, do ponto de vista institucional, poucos espaços de debates ou reflexões acerca de educação sexual - quando os têm, em geral, ocorrem apenas pela via biologizante, que naturaliza a heterossexualidade. Dado que corrobora o resultado do estudo de revisão sistemática de literatura sobre educação sexual nas escolas brasileiras realizado por Furlanetto et al (2018).

A pretensa naturalidade da pedagogia heterossexual não legitima temas e discussões que contemplam outras possibilidades de exercício da sexualidade e fluidez dos gêneros, pois circunscreve a matriz da sexualidade humana a partir de um horizonte normativo. A sexualidade distinta da heterossexualidade é permeada pelo distanciamento e invisibilização, descartada e sucumbida de qualquer discussão, como se não houvesse vida possível fora da norma (LACERDA, 2018).

Na escola do pobre, a homofobia é institucional e (re)produzida por muitos dos atores da instituição (professores, gestores, funcionários, alunos) que partem da matriz heterossexual e oprimem os meninos gays. Para Prado et al (2012), a homofobia institucional na escola mantém a inferiorização de LGBT's. Nos auxilia Junqueira (2014) quando afirma que na escola:

[...] o heterossexismo e a homofobia podem agir, de maneira sorrateira ou ostensiva, em todos os seus espaços [...], geralmente traduzida, entre outras coisas, em uma pedagogia do insulto por meio de piadas, ridicularizações, brincadeiras, jogos, apelidos, insinuações, expressões desqualificantes e desumanizantes (JUNQUEIRA, 2014, p. 193 - grifo do autor).

Os jovens ricos tiveram, ao longo do seu processo educacional, debates e discussões adequadas às práticas pedagógicas sobre temas referentes à educação sexual e aos papéis sexuais, permitindo que eles refletissem sobre ser homem e ser mulher em uma sociedade marcada pela desigualdade de sexo/gênero, homofóbica e racista. Eles trazem reflexões 
intelectualizadas acerca dos fenômenos sociais, de modo amplo. O tema educação sexual parece caminhar a partir da lógica dos direitos humanos (PAIVA et al, 2006).

O modo como a escola lida com a questão é importante, do ponto de vista pedagógico, mas também faz com que os jovens ricos tomem a questão de forma exteriorizada de suas experiências como homens gays. Esses jovens parecem ser mais distanciados de experimentações gays.

Do ponto de vista da homossexualidade, a escola do rico coloca uma regra forte: não se pode ser homofóbico. Contraditoriamente, essa regra se torna conservadora e idealista e que pouco dialoga com a realidade social. Ser homofóbico não aparece na e para a escola como possibilidade de conduta, fato que parece distanciar a escola do problema, optando-se por debates e reflexões mais abstratas sobre a questão.

Libâneo (2012) nos permite compreender, do ponto de vista estrutural, a diferença que encontramos na significação dos ricos e dos pobres no que tange à intelectualização da masculinidade de um lado (rico), e à experimentação gay de outro (pobre), quando estabelece a diferença entre as escolas do conhecimento (do rico) e do acolhimento (do pobre).

Ambos os grupos, dos jovens ricos e pobres, descobrem, ao longo de sua constituição, que há uma norma para ser homem na qual não se encaixam. Eles vão descobrindo as normas de ser homem na família, em um primeiro momento, e depois na escola, instituições marcadas pelo heteropatriarcado, que tem sua expressão máxima na violência de gênero cometida pelos homens nas diversas instituições sociais para marcar um modelo ideal de masculinidade.

Violência de gênero é o conceito mais amplo, abrangendo vítimas como mulheres, crianças e adolescentes de ambos os sexos. No exercício da função patriarcal, os homens detêm o poder de determinar a conduta das categorias sociais nomeadas, recebendo autorização ou, pelo menos, tolerância da sociedade para punir o que se Ihes apresenta como desvio. [...] a execução do projeto de dominação-exploração da categoria social homens exige que sua capacidade de mando seja auxiliada pela violência (SAFFIOTI, 2001, p. 115)

A violência de gênero extrapola o mero controle da sexualidade. Ao contrário, atua para organizar o conjunto de relações sociais, prescrevendo os modos de ser homem e ser mulher necessários para a preservação das relações patriarcais de gênero.

$\mathrm{Na}$ família, primeira instituição social com que os meninos se deparam quando encontram o mundo, é esperado que o homem reproduza determinados comportamentos. Nesse sentido, o homem gay apresenta uma postura antinatural, inclusive do ponto de vista da reprodução, ideologia que atravessa todo o tecido social e é reproduzida na escola. "A heterossexualidade aparece, assim, como o padrão para avaliar todas as outras 
sexualidades" (BORRILLO, 2010, p. 31), marcando o lugar do homem e da mulher na sociedade patriarcal.

Os jovens ricos e pobres trazem relatos de situações que ocorrem na escola e nos permitem afirmar que ela promove a heterossexualidade, tal como afirmam em seus estudos Junqueira (2014), Borges e Meyer (2008), Furlenatto et al (2018), Lacerda (2018). Ainda que o namoro comumente seja permitido nessa instituição social, tal orientação é seletiva, pois as referências seriam as relações heteroafetivas. As práticas homoafetivas são combatidas e representam focos constantes de conflitos na comunidade escolar (ABRAMOVAY; CASTRO, 2006, p. 95).

O heterossexismo que ocorre na escola e em outras instituições sociais, como a família, faz com que os meninos, muitas vezes, sofram com a decisão de assumir a homossexualidade. Sair do armário, assumir e declarar a homossexualidade na escola e na família foram preocupações demonstradas pelos jovens dos dois grupos, com modos diferentes de autodeclaração nesses espaços.

Em muitas relações, senão na maioria delas, assumir-se é uma questão de intuições ou convicções que se cristalizam, que já estavam no ar por algum tempo e que já tinham estabelecido seus circuitos de força de silencioso desprezo, de silenciosa chantagem, de silencioso deslumbramento, de silenciosa cumplicidade. (SEDGWICK, 2007, p. 38).

A revelação dos meninos gays destrói a expectativa para o sexo/gênero masculino, tensiona e provoca os espaços e, do ponto de vista individual, pode ser potente ou destrutiva das relações sociais constituídas.

Há uma norma para ser homem e uma norma para ser mulher. Os jovens participantes da pesquisa, ao longo de sua constituição na escola, foram percebendo que não cabiam nem em uma, nem em outra.

Eles não têm dúvidas de que são homens, mas são diferentes dos outros homens. Há, na escola, normas rígidas de sexo/gênero que marcam o que é ser homem e o que é ser mulher, retroalimentadas por uma educação sexista (JUNQUEIRA, 2007; 2013; LACERDA, 2018). Os meninos se constituem com outros meninos em um lugar que chamamos, com Welzer Lang (2001; 2004), de casa-dos-homens. Os jovens gays que participaram da pesquisa, ou foram expulsos dessa casa monossexuada (pobres), na escola, para se constituírem meninos gays ou nunca puderam participar dela (ricos), produzindo reflexões intelectualizadas sobre essa casa, longe dela, impedidos de estar nela.

Nós estamos, claramente, na presença de um modelo político de gestão de corpos e desejos. $\mathrm{E}$ os homens que querem viver sexualidades não-heterocentradas são 
estigmatizados como não sendo homens normais, acusados de serem passivos e ameaçados de serem associados a mulheres e tratados como elas (WELZER-LANG, 2004, p. 468).

Os meninos gays são homens dominados por outros homens, impedidos de ocuparem lugares monossexuados que constituem a masculinidade do homem heterossexual na instituição social escola. Eles não cabem na casa-dos-homens porque são como elas e sofrem homofobia, fenômeno social que existe para exercer a manutenção da masculinidade rígida e heterossexista. Abandonados por outros homens, eles ficam sem moradia e precisam se reconfigurar na casa-das-mulheres. A casa-dos-homens não lhes cabe porque não supera a rigidez masculina. Eles são inquilinos na casa-das-mulheres, mas não donos desse lar.

Gays pobres e ricos buscam uma normatividade. Se reconhecem como homens, não como os outros homens, mas sabem que não são como elas, ao mesmo tempo em que não constituem a casa-dos-gays. Eles têm medo de ser um homem que não responde à lógica machista porque parece que a experiência escolar vai dando pistas de que não responder a ela os torna não-homens. O medo de serem cobrados os faz, por um período de tempo, esconder a homossexualidade porque parece que eles precisam convencer as outras pessoas de que são homens. Ser chamado de gay por outras pessoas caminha na direção de não ser homem nem mulher e daí eles acabam temendo não ser nada. Existe um modo reproduzido pela escola, de ser homem e de ser mulher, ensinado e aprendido nas diferentes esferas escolares, mas não existe uma referência de modo homem gay de ser.

Grupos substanciais de mulheres e homens descobriram que a categoria nominativa 'homossexual', ou seus quase-sinônimos mais recentes, tem um poder real de organizar e descrever a experiência de sua própria sexualidade e identidade de modo suficiente para fazer com que sua auto-aplicação - mesmo que apenas tácita - seja, pelo menos, digna dos enormes custos que a acompanham. (SEDGWICK, 2007, p. 43).

O caminho de análise que percorremos nos permitiu conclusões acerca do singular papel da escola na constituição da masculinidade gay, marcando as diferenças entre ricos e pobres em uma sociedade fortemente caracterizada pela desigualdade social e estruturada pela consubstancialidade raça-classe-sexo/gênero.

A homossexualidade é um fenômeno social importante, vivido, também e principalmente, na escola, "e como tal, palco das mesmas disputas, paradoxos, contradições e transformações que caracterizam a sociedade como um todo" (FRY; MACRAE, 1985, p. 120).

A educação tem um papel potente em um sistema que aprofunda a desigualdade. Do ponto de vista da sexualidade, vimos que apresenta suas contradições e, na escola, podem estar as possibilidades de mudança. Concordamos com Cury (1985, p. 74) que "[...] a 
educação, longe de assegurar definitivamente e para sempre a reprodução do sistema atual, pode contribuir para sua modificação".

Com os adolescentes gays que participaram deste trabalho aprendemos que tudo que é da vida social não deve ser estranho à escola. E para que a escola possa contribuir com a modificação e superação do sistema atual, é preciso o reconhecimento da multiplicidade e complexidade das relações sociais que se apresentam na realidade, produzindo formas de impedir práticas homofóbicas, e um ambiente em que os meninos possam constituir a masculinidade com a certeza da ampla possibilidade de cores e matizes de ser homem. A escola se potencializa quando dá visibilidade às diversas e diferentes desigualdades sociais, à dominação de classe e às opressões. Desse modo, ela pode se constituir como instituição social potente na construção de uma sociedade mais igualitária.

\section{Referências}

ABRAMOVAY, Miriam.; CASTRO, Mary Garcia (Coord.). Relações raciais na escola: reprodução de desigualdades em nome da igualdade. Brasília: Observatório de Violências nas Escolas, 2006.

ABRAMOVAY, Miriam; CASTRO, Mary Garcia; SILVA, Lorena Bernadete da (Org.). Juventudes e sexualidade. Brasília: Unesco Brasil, 2004.

AGUIAR, Wanda Maria Junqueira de et al. Núcleos de significação: uma proposta históricodialética de apreensão das significações. Cadernos de Pesquisa, São Paulo, v. 45, n. 155, p. 56-75, jan/mar. 2015.

AGUIAR, Wanda Maria Junqueira de; OZELA, Sergio. Apreensão dos sentidos: aprimorando a proposta dos núcleos de significação. Revista Brasileira de Estudos Pedagógicos, Brasília, v. 94, n. 236, p. 299-322, jan/abr. 2013.

ALBERTINI, Pierre. Escuela. In: TIN, Louis-Georges (Org.). Diccionario Akal de la homofobia. Madrid: Ediciones Akal, 2012. p. 177-183.

ALMEIDA, Angela Maria de Oliveira; CUNHA, Gleicimar. Gonçalves. Representações Sociais do Desenvolvimento Humano. Psicologia: Reflexão e Crítica, Porto Alegre, v. 16, n. 1, p. 147-155, 2003. Disponível em:

http://www.scielo.br/pdf/\%0D/prc/v16n1/16806.pdf. Acesso em: 15 ago. 2020.

BOCK, Ana Mercês Bahia. As aventuras do Barão de Münchhausen na psicologia. 1. ed. São Paulo: EDUC, 1999.

BOCK, Ana Mercês Bahia. A Psicologia Sócio-Histórica: uma perspectiva crítica em psicologia. IN: Psicologia Sócio-Histórica: uma perspectiva crítica em psicologia. BOCK, Ana Mercês Bahia; GONÇALVES, Maria da Graça Marchina; FURTADO, Odair (Orgs.). 6 ed. São Paulo: Cortez, 2015, p. 21-46 
BORGES, Zulmira Newlands; MEYER, Dagmar Estermann. Limites e possibilidades de uma ação educativa na redução da vulnerabilidade à violência e à homofobia. Ensaio -

Avaliação e Políticas Públicas em Educação, Rio de Janeiro, v. 16, n. 58, p. 59-

76, mar. 2008. Disponível em: http://www.scielo.br/scielo.php?script=sci_arttext\&pid=S010440362008000100005\&lng=en\&nrm=iso. Acesso em: 09 nov. 2019.

BORGES, Zulmira Newlands et al . Percepção de professoras de ensino médio e fundamental sobre a homofobia na escola em Santa Maria (Rio Grande do Sul/Brasil). Educação revista, Curitiba, n. 39, p. 21-38, abr. 2011.

CISNE, Mirla. Relações sociais de sexo, "raça"/etnia e classe: uma análise feministamaterialista. Temporalis, Brasília, v. 14, n. 28, p. 133-149, nov. 2014. Disponível em: http://periodicos.ufes.br/temporalis/article/view/7886. Acesso em: 02 mai. 2019.

CURY, Carlos Roberto Jamil. Educação e contradição: elementos metodológicos para uma teoria crítica do fenômeno educativo. 1. ed. São Paulo: Cortez, 1985.

FALQUET, Jules. Por uma anatomia das classes de sexo: Nicole-Claude Mathieu ou a consciência das oprimidas. Tradução: Maíra Kubík Taveira Mano Mano. Lutas Sociais, São Paulo, v.18, n.32, p. 09-23, jan./jun. 2014. Disponível em:

http://www4.pucsp.br/neils/revista/vol.32/jules_falquet.pdf. Acesso em: 07 mai. 2019.

FRY, Peter; MACRAE, Edward. O que é homossexualidade. Coleção Primeiros Passos. São Paulo: Brasiliense, 1985.

FURLANETTO, Milene Fontana Et Al. Educação Sexual em Escolas Brasileiras: Revisão Sistemática da Literatura. Cadernos de Pesquisa v.48 n.168 p.550-571 abr./jun, 2018. Disponível em http://publicacoes.fcc.org.br/ojs/index.php/cp/article/view/5084/pdf. Acesso em jun. 2019.

GOMES, Ana Maria.; LUCCA, Paulo Roberto. Uma luz no fim do armário: aspectos sociais da construção do homoerotismo. In: PASSAMANI, Guilherme Rodrigues (Org.). (Contra) pontos: ensaios de gênero, sexualidade e diversidade sexual. Campo Grande, MS: Editora UFMS, 2011. p. 93-103.

GONÇALVES, Maria da Graça Marchina. A psicologia como ciência do sujeito e da subjetividade: a historicidade como noção básica. IN: Psicologia Sócio-Histórica: uma perspectiva crítica em psicologia. BOCK, Ana Mercês Bahia; GONÇALVES, Maria da Graça Marchina; FURTADO, Odair (Orgs.). 6 ed. São Paulo: Cortez, 2015a, p. 47-66.

GONÇALVES, Maria da Graça Marchina. A psicologia como ciência do sujeito e da subjetividade: o debate pós-moderno. IN: Psicologia Sócio-Histórica: uma perspectiva crítica em psicologia. BOCK, Ana Mercês Bahia; GONÇALVES, Maria da Graça Marchina; FURTADO, Odair (Orgs.). 6 ed. São Paulo: Cortez, 2015b, p. 67-93.

GONZÁLEZ REY, Fernando. Pesquisa Qualitativa e Subjetividade: os processos de construção da informação. 1. ed. São Paulo: Cengage Learning, 2005.

GONZÁLEZ REY, Fernando. As Configurações Subjetivas do Câncer: um Estudo de Casos em uma Perspectiva Construtivo-Interpretativa. Psicologia: Ciência e Profissão, Brasília, v. 30, n. 2, p. 328-345. 2010. 
GUERRA, Alexandre; POCHMANN, Marcio; SILVA, Ronnie Aldrin (Orgs.). Atlas da Exclusão Social no Brasil: dinâmica da exclusão social na primeira década do século XXI (volume 2). São Paulo: Cortez, 2015.

SOUZA, Jessé. Para compreender a desigualdade brasileira. Teoria e Cultura, v. 1, n. 2, jul./dez. 2006. p.83-100.

SOUZA, Jessé. A construção social da subcidadania: para uma sociologia política da modernidade periférica. UFMG, 2003

JUNQUEIRA, Rogerio Diniz. A Pedagogia do Armário: heterossexismo e vigilância de gênero no cotidiano escolar. Annual Review of Critical Psychology, Rio de Janeiro, v. 11, n. 10, p. 189-204. 2013.

JUNQUEIRA, Rogerio Diniz. Homofobia: limites e possibilidades de um conceito em meio a disputas. Bagoas, Natal, v. 1, n. 1, pp. 145-165, jul./dez. 2007.

KERGOAT, Danièle. Divisão sexual do trabalho e relações sociais de sexo. In: HIRATA, Helena et al (org.). Dicionário Crítico do Feminismo. 2. ed. São Paulo: UNESP, 2009. p. 67-76.

LACERDA, Milena. Enredos sobre diversidade sexual e gênero na educação. In:

NOGUEIRA, Leonardo et al (org.). Hasteemos a bandeira colorida: Diversidade sexual e de gênero no Brasil. 1. ed. São Paulo: Expressão Popular, 2018. p. 211-230.

LAPA, Thaís de Souza. Divisão Sexual do Trabalho. Processo de trabalho, divisão sexual do trabalho e práticas sociais das operárias na indústria eletroeletrônica no contexto da flexibilidade produtiva. 2015. Dissertação (Mestrado em Sociologia) - Faculdade de Filosofia, Letras e Ciências Humanas, Universidade de São Paulo, São Paulo, 2015

LIBÂNEO, José Carlos. O dualismo perverso da escola pública brasileira: escola do conhecimento para os ricos, escola do acolhimento social para os pobres. Educação e Pesquisa, São Paulo, v. 38, n. 1, p. 13-28. 2012. Disponível em:

http://www.scielo.br/pdf/ep/v38n1/aop323. Acesso em: 18 out. 2019.

MAIA, Ana Cláudia Bortolozzi et al. Educação sexual na escola a partir da psicologia histórico-cultural. Psicologia em Estudo, Maringá, v. 17, n. 1, p. 151-156, jan./mar. 2012. Disponível em: http://www.scielo.br/pdf/pe/v17n1/v17n1a16. Acesso em: 02 out. 2019.

MATHIEU, Nicole Claude ¿Identidad sexual/sexuada/de sexo? Tres modos de conceptualización de larelación entre sexo y género. In: CURIEL, Ochy; FALQUET, Jules (org.). El patriarcado al desnudo: Tres feministas materialistas. Buenos Aires: Brecha Lésbica, 2005. p. 130-175.

NETTO, José Paulo. Introdução ao Método da Teoria Social. In: Conselho Federal de Serviço Social (Org.) Direitos Sociais e Competências Profissionais. x. ed. Brasília: CFESS e ABEPSS, 2009.

PAIVA et al. O direito à prevenção e os desafios da redução da vulnerabilidade ao HIV no Brasil. Rev Saúde Pública 2006. 40(Supl):109-119. Disponível em http://www.scielo.br/pdf/rsp/v40s0/15.pdf. Acesso em mai. 2020. 
PATTEMAN, Carole. O contrato sexual. 1. ed.São Paulo: Paz e Terra, 1993. p. 38-63.

POCHMANN, Marcio; AMORIM, Ricardo (org.) Atlas da exclusão social no Brasil

(Volume 1). 1. ed. São Paulo: Cortez, 2003.

POBLETE HERNÁNDEZ, Nadia. ¿Ruptura o Continuidad?: Reflexiones en torno al Heteropatriarcado a partir de los relatos de un grupo de jóvenes infractores/as de ley. 2014. Dissertação (Magister em Estudios de Género y Cultura en América Latina, mención Ciencias Sociales), Universidad de Chile, Santiago, 2014.

PRADO, Marco Aurélio Máximo; MARTINS, Daniel Arruda; ROCHA, Leonardo Tolentino Lima. O lítigio sobre o impensável: escola, gestão dos corpos e homofobia institucional. Bagoas - Estudos gays: gêneros e sexualidades, v. 3, n. 04, 27 nov. 2012.

REIS, Aparecido Francisco; CARVALHO, Gabriel Zamian. Homofobia e sexualidade: a agressividade do "palavrão" como forma de manifestação do bullying no ambiente escolar. Interfaces da Educação, Paranaíba, v.5, n.13, p.194-207, 2014

ROSA, Elisa Zaneratto; KAHHALE, Edna Maria Severino Peters. A construção de um saber crítico em psicologia. IN: A dimensão subjetiva da realidade: uma leitura sócio-

histórica. BOCK, Ana Mercês Bahia; GONÇALVES, Maria da Graça Marchina (Orgs.). São Paulo: Cortez, 2009, p. 19-53.

SAFFIOTI, Heleieth. Contribuições feministas para o estudo da violência de gênero. IN:

Cadernos. Pagu, Campinas, n. 16, 2001. pág. 115-136

SAFFIOTI, Heleieth. O Poder do Macho. São Paulo: Moderna, 1987.

SEDGWICK, Eve Kosofsky. A epistemologia do armário. Tradução: Plínio Dentzien. In: Cadernos Pagu, Campinas: Núcleo de Estudos de Gênero Pagu, 2007. p. 19-54, 2007.

TIN, Louis-Geroge. Heterossexismo. In: TIN, Louis-Geroge (Org.). Diccionario akal de la homofobia. 1. ed. Madrid: Ediciones Akal, 2012. p. 260-63.

WELZER-LANG, Daniel. A construção do masculino: dominação das mulheres e homofobia. Estudos Feministas, v. 9, n. 2, p. 460-482, 2001. Disponível em: http://www.scielo.br/pdf/ref/v9n2/8635. Acesso em: 06 mar. 2020.

WELZER-LANG, Daniel. Os homens e o masculino numa perspectiva de relações sociais de sexo. In: SHHPUN, Mônica (org.). Masculinidades. 1. ed. São Paulo: Boitempo, 2004. p. 107-128. 